\title{
Dynamics of the growth processes of Prunus armeniaca L. seedlings in the conditions of Inner Mountain Dagestan
}

\author{
Ruslan M. Osmanov ${ }^{1, *}$, Dzhalaludin M. Anatov ${ }^{2}$ \\ ${ }^{1}$ Mountain Botanical Garden DFRS RAS, str. 75 Yaragskogo, Makhachkala, 367000, Russia \\ ${ }^{2}$ Dagestan Federal Research Centre RAS, str. 45 M. Gadjiyeva, Makhachkala, 367000, Russia
}

\begin{abstract}
The paper presents the results of assessing the dynamics of growth processes 364 seedlings of 16 apricot samples under conditions of a critical altitude level for them in Dagestan $(1900 \mathrm{~m})$. A comparative study of apricot samples showed that during the growing season, annual seedlings form a small height of the main shoot (18.7-28.7 cm), subramose (0.4-2.7) and leafiness (14.7-23.6). Analysis of the relative dynamics of shoot growth showed that the maximum growth was observed in May-June $(62.8-95.7 \%)$ and low in July-September (1.0-24.5\%). A reliable correlation was established between the relative growth of the studied samples and their winter hardiness, namely, the higher the relative increase in July-September, the lower the winter hardiness. The correlation in MayJune was $-0.77^{* *}$, and in July and September $0.62^{*}$ and 0.64 **, respectively. The experiment showed the information content of studying the growth of shoot length as a diagnostic feature in assessing the winter hardiness of apricot seedlings in the mountainous conditions of Dagestan.
\end{abstract}

\section{Introduction}

The study of plant growth processes has led to the development of new approaches in adaptive gardening. At the same time, special attention is focused on the growth and development of morphological characters of a certain species, intraspecific variability, associated in the future with applied aspects [1].

One of the known methods for studying the variability and growth processes of plants is the cultivation of plants (samples) of the same species in the same agro-climatic zone, which is the basis for interpreting the data obtained for certain conditional factors. However, experiments of this kind do not take into account the complex of adaptive features that can exist in natural conditions [2, 3].

The basis for adaptive success in the study of plant species is not only the initial growth activity, but also the growth dynamics of seasonal changes [4-6]. Moreover, young plants must go through early stages of life before they mature and begin to reproduce, which allows them to expand their range [7,8].

It follows from all this that adaptive mechanisms to local climatic conditions are one of

\footnotetext{
*Corresponding author: ru.osmanov@mail.ru
} 
the important factors in the domestication of wild-growing useful plants. And on the basis of the ecological and genetic differentiation of individual species within their ranges, supplemented by experimental methods to study the growth of the shoot system, it is possible to extract some hidden resources of intraspecific variability, breeding transformations that entail dramatic changes in the productivity and resistance of many cultivated plants, including genetic resources of wild-growing apricot [9-11].

Apricot (Prunus armeniaca L.) of Dagestan is a member of the Iranian-Caucasian ecogeographical group (Dagestan subgroup) [12]. The long history of apricot cultivation and its importance for the population led to the creation of a large assortment (Shindakhlan, Hekobarsh, Honobakh, Tamasha, Uzden, etc.) [13]. Wild apricot is distributed in the valleys of the rivers Avarian Kojsu, Andijsky Kojsu, Kazikumuhsky Kojsu and KaraKojsu, at altitudes of 350-1500 m above sea level, occasionally (singularly) along the southern slopes up to $1900 \mathrm{~m}$, preferring limestone slopes of various exposures [14]. At the same time, local varieties, including the discovered valuable natural forms, are of significant scientific interest, both in the analytical and in the purposeful breeding process.

The purpose of this work is a comparative study of the dynamics of growth processes of apricot seedlings of Dagestan origin in the conditions of Inner Mountain Dagestan.

\section{Material and methods}

An experiment to assess the growth processes of apricot seedlings was carried out in the conditions of the Gunib experimental base at an altitude of $1900 \mathrm{~m}$ above sea level in 2013. The objects of research were apricot seedlings of Dagestan origin. Natural samples were obtained from the following altitude levels (m): 700 - ancient (Dagestan) varieties Shindakhlan and Kakh; 750 - Kurmi 2, 3, 4, 7 and 8; 950 - Tashkapur; 1000 - Khindakh 1, 4, Wild X1 and Wild X2; 1100 - Goor 1, 2 and 3; 1100 - sample from the Tsudakhar Experimental Base (CEB).

All counts were carried out in accordance with the generally accepted methods of studying fruit crops $[16,17,18]$. Shoot length $(\mathrm{cm})$, number of leaves, and number of side shoots were measured for each seedling. Winter hardiness was assessed by the ratio of the frozen part of the shoot to its total length in 2014-2017.

Statistical processing of experimental data (correlation, variance and cluster analyzes) was carried out using the Statistica v.13 software package.

\section{Results and discussion}

In general, the assessment of the initial growth activity of apricot seedlings showed a good germination rate of apricot seedlings under the conditions of the Gunib experimental base $68.6 \%$, but if we compare the germination capacity of cultivated samples and wild ones, then the germination capacity of the latter is higher (73.0\%) with a range of 23.8 up to $96.0 \%$. This is probably due to the high adaptive potential of wild apricot forms in terms of germination energy.

In a comparative analysis of the morphological characteristics of apricot seedlings (Table 1), the highest average values at the end of the growing season along the length of the shoot $(\mathrm{cm})$ were four samples: Goor 1 (28.3), Khindakh 1 (28.7), Kurmi 2 (27.7) and Wild X1 (27.4). In terms of the number of leaves, the maximum values are observed in the aforementioned accessions, as well as in Goor 3 and Wild X2, while the minimum values were observed in the seedlings of the Kurmi 8, Tashkapur, and Khindakh 4. According to the number of side shoots, the maximum values of the samples Tashkapur (2.8), Goor 3 (2.7) and Shindakhlan (2.6), and the minimum - Kurmi 3 (0.3), Kurmi 8 (0.6) and Wild X2 
$(0.4)$.

Table 1. Comparative assessment of morphometric characteristics of apricot of Dagestan origin in the conditions of the Gunib experimental base at the end of the growing season

\begin{tabular}{|l|c|c|c|c|c|c|c|}
\hline \multirow{2}{*}{$\begin{array}{l}\text { Name } \\
\text { samples }\end{array}$} & \multirow{2}{*}{} & \multicolumn{2}{l|}{ Shoot length, cm } & \multicolumn{2}{l|}{ Number of leaves } & \multicolumn{2}{l|}{ Number of side shoots } \\
\cline { 3 - 8 } & & $\mathbf{X} \pm \mathbf{S x}$ & $\mathbf{C V}, \mathbf{\%}$ & $\mathbf{X} \pm \mathbf{S x}$ & $\mathbf{C V ,} \%$ & $\mathbf{X} \pm \mathbf{S x}$ & $\mathbf{C V ,} \%$ \\
\hline Shindakhlan & 15 & $24.7 \pm 2.04$ & 32.0 & $20.2 \pm 1.72$ & 28.0 & $2.6 \pm 0.59$ & 86.0 \\
\hline Goor 1 & 30 & $28.3 \pm 0.95$ & 18.3 & $23.6 \pm 0.96$ & 22.3 & $1.1 \pm 0.20$ & 100.1 \\
\hline Goor 2 & 20 & $25.5 \pm 1.48$ & 26.0 & $17.5 \pm 1.34$ & 34.1 & $1.0 \pm 0.27$ & 117.5 \\
\hline Goor 3 & 15 & $25.1 \pm 1.78$ & 27.0 & $22.8 \pm 1.87$ & 31.8 & $2.7 \pm 0.40$ & 57.7 \\
\hline Wild X1 & 30 & $27.4 \pm 0.88$ & 17.6 & $18.4 \pm 0.84$ & 25.0 & $1.4 \pm 0.27$ & 103.9 \\
\hline Wild X2 & 30 & $22.1 \pm 0.92$ & 22.8 & $19.2 \pm 1.08$ & 30.8 & $0.4 \pm 0.13$ & 180.9 \\
\hline Kakh & 20 & $24.7 \pm 1.38$ & 25.0 & $17.3 \pm 1.37$ & 35.4 & $1.4 \pm 0.36$ & 116.7 \\
\hline Kurmi 2 & 20 & $27.7 \pm 1.44$ & 23.0 & $23.6 \pm 1.87$ & 23.5 & $1.5 \pm 0.51$ & 148.7 \\
\hline Kurmi 3 & 30 & $20.8 \pm 0.82$ & 21.6 & $19.2 \pm 1.08$ & 31.0 & $0.3 \pm 0.09$ & 178.3 \\
\hline Kurmi 4 & 16 & $27.3 \pm 2.49$ & 36.5 & $20.7 \pm 2.23$ & 43.1 & $1.1 \pm 0.38$ & 137.2 \\
\hline Kurmi 7 & 18 & $18.7 \pm 1.17$ & 27.7 & $15.8 \pm 1.28$ & 34.5 & $0.6 \pm 0.18$ & 157.1 \\
\hline Kurmi 8 & 20 & $19.2 \pm 0.63$ & 14.6 & $13.0 \pm 0.88$ & 30.2 & $1.1 \pm 0.21$ & 87.9 \\
\hline Tashkapur & 30 & $21.9 \pm 0.65$ & 16.2 & $14.7 \pm 0.64$ & 23.8 & $2.8 \pm 0.41$ & 79.7 \\
\hline Khindakh 1 & 20 & $28.7 \pm 1.85$ & 28.8 & $18.7 \pm 1.42$ & 34.1 & $2.0 \pm 0.50$ & 112.3 \\
\hline Khindakh 4 & 30 & $25.6 \pm 0.53$ & 11.4 & $15.1 \pm 0.78$ & 28.5 & $1.5 \pm 0.30$ & 108.2 \\
\hline TsEB & 20 & $18.7 \pm 1.46$ & 34.8 & $16.4 \pm 1.32$ & 35.9 & $0.9 \pm 0.29$ & 148.1 \\
\hline$\sum$ & 364 & $24.1 \pm 0.34$ & 27.2 & $18.4 \pm 0.33$ & 34.3 & $1.3 \pm 0.08$ & 124.5 \\
\hline
\end{tabular}

The coefficients of variation $(\mathrm{CV})$ of the considered traits: "shoot length" and "number of leaves" have a wide range of values of the relative variability of seedlings (11.4-36.5\% for the length of the shoots and 22.3-43.1 for the number of leaves). With regard to the number of side shoots, the variation is very high; the variability of this trait is significantly influenced by the micro conditions on the Gunib plateau and a large number of zero values.

Based on the results on the relative dynamics of the shoot length for three months (Fig. 1), it can be argued that apricot seedlings are characterized by the maximum growth of shoots in May-June (62.8-95.7\%). On the contrary, in July-September the growth of shoots is much lower (1.0-24.5\%). Thus, the maximum growth of the one-year apricot shoot in the mountainous conditions of Dagestan (above $1800 \mathrm{~m}$ ) is formed in May-June.

If we compare the findings on the relative increase in shoot length by months with their winter hardiness, which were considered in our previously published article [18], then there is a tendency to decrease the relative freezing of shoots in the samples with the smallest increase in July-September $(<10 \%)$. So, in the samples of Khindakh 4 Kurmi 8 , frost pockets of shoots was 1.0 and $9.4 \%$, respectively, and the relative increase in JulySeptember was 3.9 and $7.3 \%$, respectively.

In non-frost-resistant samples Kurmi 2 and Kurmi 4, the growth in July September was $36.8-41.0 \%$, with freezing $27.4-32.6 \%$. Correlation analysis for the averaged values of the samples and the exponential population confirmed the relationship between the relative growth and frost pockets.

For the averaged values, the reliable correlations between them in June were $r=$ $0.77^{* *}$, and the positive reliable correlations with July and September $(0.62 *$ and $0.64 * *$, respectively). For the exponential population (364 seedlings), these values are respectively $\left(-0.34 * * * ; 0.28^{* * *}\right.$ and $0.30^{* * *}$, respectively, for June, July and September). 


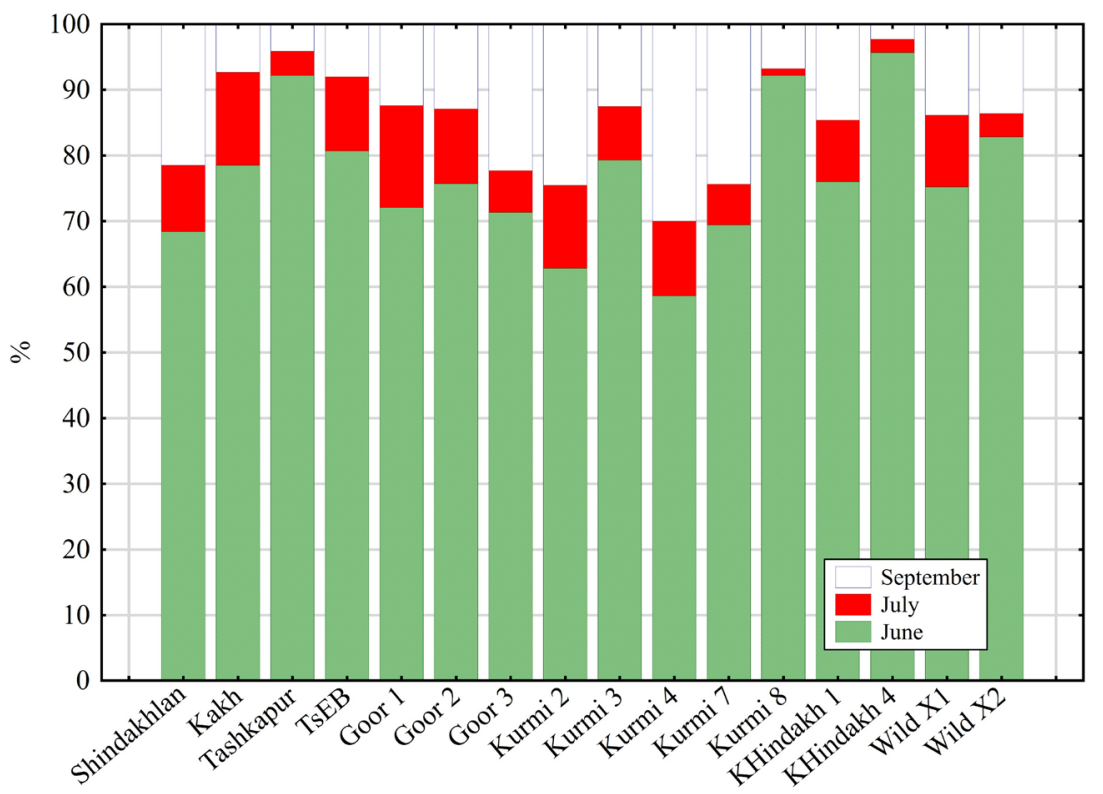

Fig. 1. The dynamics of the growth of the shoot length over three months (in percent)

One-way ANOVA test of variance showed (Table 2) that the strength of the factor $\left(\mathrm{h}^{2}\right)$ was from $20.2 \%$ for the number of lateral shoots to $53.5 \%$ for the length of the shoot. The largest differences in the comparative three months of the relative components of the variance were revealed in June and decrease by September.

Table 2. Analysis of variance (ANOVA) based on the characteristics of apricot seedlings

\begin{tabular}{|l|l|l|l|l|l|l|l|}
\hline Months & Traits & $\begin{array}{l}\text { SS } \\
\text { Effect }\end{array}$ & $\begin{array}{l}\text { SS } \\
\text { Error }\end{array}$ & $\begin{array}{l}\text { MS } \\
\text { Effect }\end{array}$ & $\begin{array}{l}\text { MS } \\
\text { Error }\end{array}$ & $\begin{array}{l}\text { F- } \\
\text { criterion }\end{array}$ & $\mathbf{h}^{\mathbf{2}}$ \\
\hline \multirow{5}{*}{ June } & Shoot length & 2829,27 & 2459,82 & 188,618 & 7,07 & 26,68 & $53,5^{* * *}$ \\
\cline { 2 - 8 } & Number of leaves & 1331,22 & 2652,06 & 88,748 & 7,62 & 11,65 & $33,4^{* * *}$ \\
\cline { 2 - 8 } & Number of side shoots & 229,38 & 759,16 & 15,292 & 2,18 & 7,00 & $23,2^{* * *}$ \\
\hline \multirow{3}{*}{ July } & Shoot length & 3368,70 & 5671,151 & 224,58 & 16,30 & 13,78 & $37,2^{* * *}$ \\
\cline { 2 - 8 } & Number of leaves & 1361,21 & 4882,782 & 90,74733 & 14,03 & 6,47 & $21,8^{* * *}$ \\
\cline { 2 - 8 } & Number of side shoots & 223,30 & 851,815 & 14,88667 & 2,45 & 6,08 & $20,7^{* * *}$ \\
\hline \multirow{3}{*}{ September } & Shoot length & 4188,78 & 11529,79 & 279,252 & 33,13 & 8,43 & $26,6^{* * *}$ \\
\cline { 2 - 8 } & Number of leaves & 3358,48 & 11168,05 & 223,8987 & 32,09 & 6,98 & $23,1^{* * *}$ \\
\cline { 2 - 8 } & Number of side shoots & 214,15 & 844,78 & 14,27667 & 2,43 & 5,88 & $20,2^{* * *}$ \\
\hline
\end{tabular}

Note: $\mathrm{df}=15 ; \mathrm{n}=364 ; \mathrm{h}^{2}-$ force of influence of factor "samples"; $* * *-\mathrm{P}<0,001$ (grade significance)

Based on the results of cluster analysis of samples at the end of the growing season, it was found that the main feature by which apricot samples are grouped is "number of side shoots" (Fig. 2). 


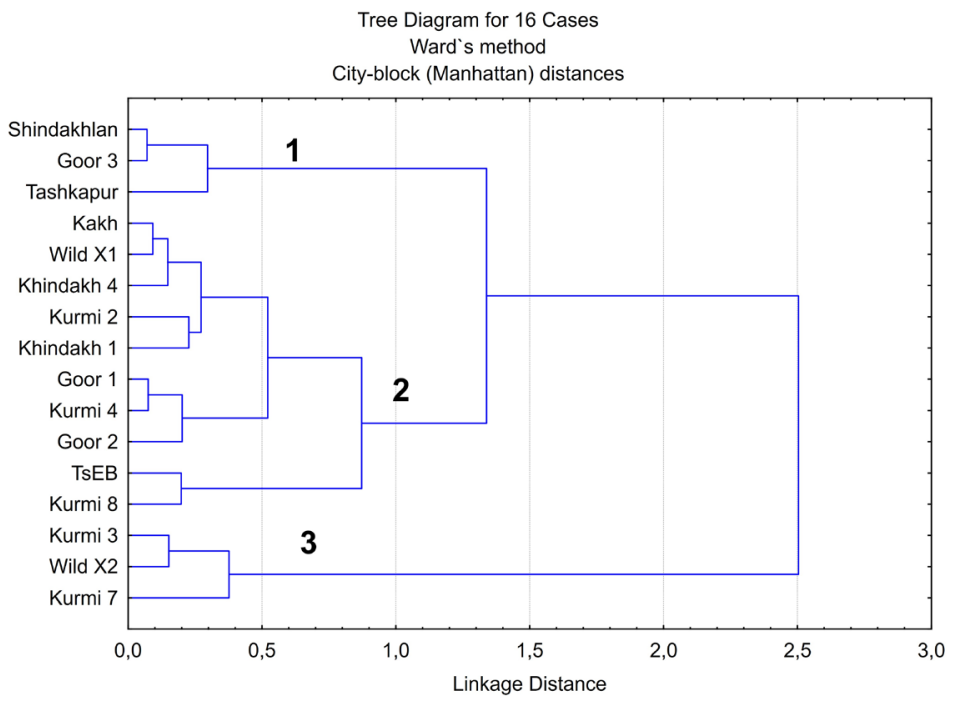

Fig. 2. Cluster analysis diagram for morphological characteristics

The conducted cluster analysis revealed groups according to the studied characteristics. The first cluster included samples with high rates in the number of side shoots. In the second cluster, this in turn differentiated into three sub clusters according to shoot length and partly according to the number of leaves. The third cluster included samples with the lowest values for the number of side shoots and the length of the main shoot. The differentiation of the samples was based largely on the number of lateral shoots; the other two characters were of secondary importance.

\section{Conclusions}

A comparative study of annual apricot plants based on quantitative traits and growth processes under conditions of a critical altitude level for them $(1900 \mathrm{~m})$ showed that during the growing season seedlings form a small height of the main shoot $(18.7-28.7 \mathrm{~cm})$, subramose (0.4-2.7) and leafiness (14.7-23.6).

Variations in the length of shoots and the number of leaves of seedlings by the coefficient of variation (CV) have a wide range of values from low to high (11.4-36.5\% for the length of the shoots and 22.3-43.1 for the number of leaves), and very high variability the number of side shoots, the variability of which is significantly influenced by the micro conditions of cultivation and the presence of a large number of zero values.

Analysis of the relative dynamics of shoot growth showed that the maximum growth of a one-year apricot shoot in the mountainous conditions of Dagestan (above $1800 \mathrm{~m}$ ) is formed in May-June (62.8-95.7\%) and low in July-September (1.0-24.5\%).

When comparing the data on the relative increase in the studied samples with the subsequent assessment of winter hardiness, a reliable relationship was established, namely, the greater the increase in percentage in July-September, the lower the winter hardiness. Correlation analysis revealed significant links between frost pockets and the growth of all months, negative with June $\left(\mathrm{r}=-0.77^{* *}\right)$, and positive with July and September $(0.62 *$ and $0.64 * *$, respectively) for averaged values and $-0.34 * * * ; 0.28 * * *$ and $0.30 * * *$ for the exponential population (364 seedlings). The findings of great interest for establishing patterns and developing a technology for isolating donors of winter hardiness when promoting apricot culture to high-altitude or northern regions and represent a platform for 
further research.

\section{Acknowledgements}

The work was supported by RFBR grant №19-016-00133A.

\section{References}

1. E. Costes, P-E. Lauri, J.L. Regnard, In: J.Janick (Ed.) Horticultural reviews, Vol. 32 (John Wiley \& Sons, Inc., 1-61, 2010) https://doi.org/10.1002/9780470767986.ch1

2. A. Fuentes-Ramírez, A. Pauchard, L.A. Cavieres, R.A. García, For. Ecol. Manag, 261(6), 1003-1009 (2011) https://doi.org/10.1016/j.foreco.2010.12.018

3. T.G. Zimmermann, A.C.S. Andrade, D.M. Richardson, Biol. Invasions, 19, 109-129 (2017) https://doi.org/10.1007/s10530-016-1267-2

4. W.K. Silk, M. Bogeat-Triboulot, Plant Soil, 374, 1-17 (2014) https://doi.org/ 10.1007/s11104-013-1726-9

5. J.J. Lembrechts, A. Pauchard, J. Lenoir, M.A. Nuñez, C. Geron, A. Ven, P. Bravo-Monasterio, E. Teneb, I. Nijs, A. Milbau, Proc. Natl. Acad. Sci., 113, 140614066 (2016) https://doi.org/10.1073/pnas.1608980113

6. B. Arsova, K.J. Foster, M.C. Shelden, H. Bramley, M. Watt, New Phytol., 225(3), 1111-1119 (2020) https://doi.org/10.1111/nph.15955

7. D.L. Vergara-Tabares, J. Badini, S.I. Peluc, Biol Invas., 18, 677-687 (2015) https://doi.org/10.1007/s10530-015-1039-4

8. D.M. Richardson, P. Pyšek, New Phytol., 196(2), 383-396 (2012) https://doi.org/ 10.1111/j.1469-8137.2012.04292.x

9. S. Decroocq, A. Cornille, D. Tricon, S. Babayeva, A. Chague, J-P. Eyquard, R. Karychev, S. Dolgikh, T. Kostritsyna, S. Liu, W. Liu, W. Geng, K. Liao, B.M. Asma, Z. Akparov, T.Giraud, V. Decroocq, Mol. Ecol., 25, 4712-4729 (2018) https://doi.org/10.1111/mec.13772

10. H. Bourguiba, A. Lasnier, B. Krška, T. Zhebentyaeva, A. Remay, C. D’Onofrio, C.A. Ledbetter, H. Iketani, D. Christen, W. Liu, G. Roch, J.M. Audergon, Acta Hortic., 1214, 203-206 (2018) https://doi.org/10.17660/ActaHortic.2018.1214.35

11. A. Kumar, E. Shahnaz, Indian Journal of Agricultural Sciences, 83(11), 1253-1256 (2013) https://www.researchgate.net/publication/289059408

12. K.U. Yilmaz, K. Gurcan, In: Mahmut Çalışkan (ed.) Genetic Diversity in Plants, (IntechOpen, 249-270, 2012) http://doi.org/10.5772/33361

13. Z.M. Asadulaev, D.M. Anatov. and M.A. Gaziev, Acta Hort, 1032, 183-190 (2014) https://doi.org/10.17660/ActaHortic.2014.1032.24

14. Z.M. Asadulaev, D.M. Anatov, Arid Ecosyst., 9(2), 104-110 (2019) https://link.springer.com/article/10.1134\%2FS2079096119020021

15. B. Krška, In: J. Soneji, M. Nageswara-Rao, Breeding and Health Benefits of Fruit and Nut Crops, (IntechOpen, 63-82, 2018) http://dx.doi.org/10.5772/intechopen.77125

16. C. Guo, Z.L. Wang, J.Q. Lu, Journal of Forestry Research, 21, 492-496 (2010) https://doi.org/10.1007/s11676-010-0104-1

17. D.M. Anatov, R.M. Osmanov, Proceedings of the Kuban State Agrarian University, 4(73), 12-16 (2018) https://doi.org/10.21515/1999-1703-73-12-16 
18. R.M. Osmanov, D.M. Anatov, Botanical herald of the North Caucasus, 2, 39-45 (2019) http://botvestnik.ru/files/Botanical_Herald_North_Caucasus_20192.pdf 